\title{
Central GLP-1 receptor signalling accelerates plasma clearance of triacylglycerol and glucose by activating brown adipose tissue in mice
}

\author{
Sander Kooijman $^{1,2}$ • Yanan Wang ${ }^{1,2} \cdot$ Edwin T. Parlevliet $^{1,2,3}$ • Mariëtte R. Boon ${ }^{1,2}$ • \\ David Edelschaap $^{1,2}$ • Gido Snaterse ${ }^{1,2} \cdot$ Hanno Pijl ${ }^{1}$ • Johannes A. Romijn ${ }^{3}$. \\ Patrick C. N. Rensen ${ }^{1,2}$
}

Received: 20 March 2015 / Accepted: 23 July 2015 /Published online: 9 August 2015

(C) The Author(s) 2015. This article is published with open access at Springerlink.com

\begin{abstract}
Aims/hypothesis Glucagon-like peptide 1 (GLP-1) receptor (GLP-1R) agonism, used in the treatment of type 2 diabetes, has recently been shown to increase thermogenesis via the brain. As brown adipose tissue (BAT) produces heat by burning triacylglycerol (TG) and takes up glucose for de novo lipogenesis, the aim of this study was to evaluate the potential of chronic central GLP-1R activation by exendin- 4 to facilitate clearance of lipids and glucose from the circulation by activating BAT.

Methods Lean and diet-induced obese (DIO) C57Bl/6J mice were used to explore the effect of a 5 day intracerebroventricular infusion of the GLP-1 analogue exendin- 4 or vehicle on lipid and glucose uptake by BAT in both insulin-sensitive and insulin-resistant conditions.

Results Central administration of exendin-4 in lean mice increased sympathetic outflow towards BAT and white adipose tissue (WAT), resulting in increased thermogenesis as evidenced by increased uncoupling protein 1 (UCP-1) protein levels and decreased lipid content, while the uptake of TGderived fatty acids was increased in both BAT and WAT.
\end{abstract}

Sander Kooijman, Yanan Wang and Edwin T. Parlevliet contributed equally to this study.

Sander Kooijman

s.kooijman@lumc.nl

1 Department of Medicine, Division of Endocrinology, Leiden University Medical Center, Room C7-Q44, Albinusdreef 2, PO Box 9600, 2300 RC Leiden, the Netherlands

2 Einthoven Laboratory for Experimental Vascular Medicine, Leiden University Medical Center, Leiden, the Netherlands

3 Department of Medicine, Academic Medical Center, Amsterdam, the Netherlands
Interestingly, in DIO mice, the effects on WAT were blunted, while exendin-4 still increased sympathetic outflow towards BAT and increased the uptake of plasma TG-derived fatty acids and glucose by BAT. These effects were accompanied by increased fat oxidation, lower plasma TG and glucose concentrations, and reduced body weight.

Conclusions/interpretation Collectively, our results suggest that BAT activation may be a major contributor to the glucose- and TG-lowering effects of GLP-1R agonism.

Keywords Brown adipose tissue $\cdot$ Exendin-4 · GLP-1 · Mice · Triacylglycerol

\begin{tabular}{|c|c|}
\hline \multicolumn{2}{|c|}{ Abbreviations } \\
\hline$\left[{ }^{14} \mathrm{C}\right] \mathrm{DG}$ & $2-\left[1-{ }^{14} \mathrm{C}\right]$ Deoxy-D-glucose \\
\hline$\left[{ }^{3} \mathrm{H}\right] \mathrm{TO}$ & Glycerol tri $\left[9,10(n)-{ }^{3} H\right]$ oleate \\
\hline $\mathrm{aCSF}$ & Artificial cerebrospinal fluid \\
\hline BAT & Brown adipose tissue \\
\hline $\mathrm{DIO}$ & Diet-induced obese \\
\hline GLP-1 & Glucagon-like peptide-1 \\
\hline GLP-1R & Glucagon-like peptide-1 receptor \\
\hline gWAT & Gonadal white adipose tissue \\
\hline iBAT & Interscapular brown adipose tissue \\
\hline i.c.v. & Intracerebroventricular \\
\hline RER & Respiratory exchange ratio \\
\hline sBAT & Subscapular brown adipose tissue \\
\hline SNS & Sympathetic nervous system \\
\hline sWAT & Subcutaneous white adipose tissue \\
\hline TG & Triacylglycerol \\
\hline $\mathrm{TH}$ & Tyrosine hydroxylase \\
\hline TRL & Triacylglycerol-rich lipoprotein \\
\hline UCP-1 & Uncoupling protein-1 \\
\hline WAT & White adipose tissue \\
\hline
\end{tabular}




\section{Introduction}

Glucagon-like peptide-1 (GLP-1) receptor (GLP-1R) agonists, such as exendin- 4 , have been used in the treatment of type 2 diabetes; they increase glucose-dependent insulin secretion, regulate gastric emptying and reduce food intake and body weight [1]. At least some of these actions are mediated through neuroendocrine mechanisms, as shown by rodent studies, consistent with the notion that GLP-1R is highly expressed in the hypothalamus. Intracerebroventricular (i.c.v.) administration of GLP-1 reduces food intake and body weight $[2,3]$. Moreover, the central GLP-1R signalling system is linked to the control of peripheral glucose metabolism by inhibiting non-insulin-mediated glucose uptake by muscle and increasing insulin secretion from the pancreas $[4,5]$. Previously, we have shown that subcutaneous GLP-1 treatment reduces hepatic glucose production in mice, partly through central GLP-1R signalling [6]. Hence, one of the functions of the central GLP-1R system is the modulation of the metabolic activity in peripheral organs that are crucial for the maintenance of energy homeostasis.

Brown adipose tissue (BAT) is a regulator of overall energy homeostasis by combusting triacylglycerol (TG) and glucose into heat. Enhancement of the thermogenic capacity of BAT induces weight loss through increased energy expenditure [7, $8]$ and lowers the plasma levels of TG and glucose. In fact, BAT activation can correct hyperlipidaemia [9] and hyperglycaemia [10] by increased uptake of TG-derived fatty acids [11] and glucose from plasma. Recently, it has been shown that activation of central GLP-1R increases thermogenesis in BAT and induces browning within white adipose tissue (WAT), and that this correlates with increased expression of genes required for thermogenesis, including uncoupling protein-1 [12, 13]. While these findings suggest an important role of the central GLP-1R system in BAT activation, the effect of central GLP-1R activation on lipid and glucose control by BAT has not yet been investigated. Furthermore, although GLP-1R agonists are implemented to treat type 2 diabetes, the responsiveness of the central GLP-1R system to activate BAT to take up TG-derived fatty acids and glucose under central insulin resistance [14] is unknown.

The aim of this study was to evaluate the potential of activating central GLP-1R by exendin-4 to facilitate clearance of lipids and glucose from the circulation by activating BAT, under both insulin-sensitive and insulin-resistant conditions in diet-induced obese (DIO) $\mathrm{C} 57 \mathrm{Bl} / 6 \mathrm{~J}$ mice.

\section{Methods}

Animals For all experiments, 20-week-old male C57Bl/6J mice (Charles River, Saint-Germain-Nuelles, France) were used, housed with a regular 12:12 h light/dark cycle in a temperature- and humidity-controlled environment, with free access to food and water unless noted otherwise. For dietinduced obesity, mice were fed a high-fat diet (44\% energy derived from bovine fat; Hope Farms, Woerden, the Netherlands) for 12 weeks, starting at 8 weeks of age. All animal experiments were performed in accordance with the regulations of the Dutch law on animal welfare, and the Institutional Ethics Committee for Animal Procedures, Leiden University Medical Center, Leiden, the Netherlands, approved the protocol.

Intracerebroventricular surgery and treatment Mice were randomised based on body weight, anaesthetised and cannulas (Brain Infusion Kit 3, ALZET Cupertino, CA, USA) were stereotactically implanted into the left lateral ventricle of the brain (coordinates $-0.45 \mathrm{~mm}$ anteroposterior, $-1.00 \mathrm{~mm}$ lateral and $2.50 \mathrm{~mm}$ dorsoventral from bregma). Osmotic minipumps (Model 1004, Alzet, CA, USA) attached to the cannula via a catheter were implanted subcutaneously on the back, slightly posterior to the scapulae. The catheter connected to the osmotic minipump was filled with artificial cerebrospinal fluid (aCSF; Harvard Apparatus, Holliston, MA, USA) to delay the start of drug delivery by 2 days. The minipump assured continuous delivery of $0.75 \mathrm{nmol} /$ day exendin- 4 (Bachem, Weil am Rhein, Germany) dissolved in aCSF or aCSF only. The dose of exendin-4 was expected to suppress food intake. Therefore, an aCSF-receiving pair-fed control group (restricted to the same amount of food each day as consumed by the i.c.v. exendin-4-infused mice) was also included. Because of the inclusion of a pair-fed group, blinding to group assignment was not feasible. Body weight and food intake were measured daily. One lean mouse (assigned to exendin-4 group) and three obese mice (assigned to control group) were excluded from the study because of complications after surgery. After 5 days of intervention, TG and glucose clearance was determined as described below.

Triacylglycerol and glucose clearance Triacylglycerol-rich lipoprotein (TRL)-like particles were prepared from $100 \mathrm{mg}$ of total lipid including glycerol trioleate (triolein; $70 \mathrm{mg}$ ), egg yolk phosphatidylcholine $(22.7 \mathrm{mg})$, lysophosphatidylcholine $(2.3 \mathrm{mg})$, cholesteryl oleate $(3.0 \mathrm{mg})$ and cholesterol $(2.0 \mathrm{mg})$, with addition of glycerol tri $\left[{ }^{3} \mathrm{H}\right]$ oleate $\left(\left[{ }^{3} \mathrm{H}\right] \mathrm{TO}\right)(3.7 \mathrm{MBq})$. The emulsion was sonicated and fractionated by consecutive density gradient ultracentrifugation steps [15]. The emulsion fraction containing TRL-like particles with an average size $80 \mathrm{~nm}$ was isolated and mixed with $2-\left[1-{ }^{14} \mathrm{C}\right]$ deoxy-D-glucose $\left(\left[{ }^{14} \mathrm{C}\right] \mathrm{DG}\right)$ in a 3:1 ratio based on radioactive count. Emulsions were stored at $4{ }^{\circ} \mathrm{C}$ under argon and used for in vivo kinetic experiments within 5 days following preparation.

Animals were fasted for $4 \mathrm{~h}$. At $t=0$, blood was drawn via the tail vein to determine, via enzymatic assays, basal plasma TG (Roche Molecular Biochemicals, Indianapolis, IN, USA) 
and glucose (Instruchemie, Delfzijl, the Netherlands). Mice then received an i.v. injection of TRL-like particles ( $1 \mathrm{mg}$ TG) and $\left[{ }^{14} \mathrm{C}\right] \mathrm{DG}$. Blood samples were taken from the tail vein at 2, 5, 10 and $15 \mathrm{~min}$ after injection, and plasma ${ }^{3} \mathrm{H}$ and ${ }^{14} \mathrm{C}$ activities were counted. After the last blood sample, the mice were killed, perfused via the heart with ice-cold PBS and various organs were collected. Organs were dissolved overnight at $60^{\circ} \mathrm{C}$ in Tissue Solubilizer (Amersham Biosciences, Roosendaal, the Netherlands), and ${ }^{3} \mathrm{H}$ and ${ }^{14} \mathrm{C}$ activities were counted. Uptake of $\left[{ }^{3} \mathrm{H}\right] \mathrm{TO}$ - and $\left[{ }^{14} \mathrm{C}\right] \mathrm{DG}$-derived radioactivity by the organs was calculated from the ${ }^{3} \mathrm{H}$ and ${ }^{14} \mathrm{C}$ activities in each organ and expressed as percentage of injected dose per g wet tissue weight.

Body composition After the treatment period, body composition (lean and fat mass) was determined in conscious DIO mice using an EchoMRI-100 (EchoMRI, Houston, TX, USA).

Indirect calorimetry During the treatment period of the DIO mice, oxygen uptake $\left(\dot{V} \mathrm{O}_{2}\right)$, carbon dioxide production $\left(\dot{V} \mathrm{CO}_{2}\right)$ and physical activity were measured in metabolic cages (LabMaster System, TSE Systems, Bad Homburg, Germany). The average respiratory exchange ratio (RER), energy expenditure and carbohydrate and fat oxidation rates were calculated from day 1 to day 4 of treatment, as described previously [16].

Histology Formalin-fixed paraffin-embedded interscapular BAT (iBAT) and subcutaneous WAT (sWAT) tissue sections $(5 \mu \mathrm{m})$ were stained with haematoxylin and eosin (H\&E) using standard protocols. For staining of UCP-1 and tyrosine hydroxylase $(\mathrm{TH})$, sections were dewaxed, rehydrated and treated with peroxidase. Antigen retrieval was accomplished in $10 \mathrm{mmol} / \mathrm{l}$ citrate buffer $(\mathrm{pH}=6.0)$. Slides were blocked with normal goat serum (UCP-1) or BSA (TH) and incubated overnight at $4{ }^{\circ} \mathrm{C}$ with anti-UCP-1 antibodies (1:4,000; Ab10983; Abcam, Cambridge, UK) or anti-TH antibodies (1:2,000; Ab112; Abcam). Next, sections were incubated for 30 min with biotinylated goat $\alpha$-rabbit secondary antibodies (UCP-1; 1:600; Vector Labs, Burlingame, CA, USA) or DAKO EnVision anti-rabbit antibodies (DAKO, Glostrup, Denmark). Immunostaining was amplified and visualised using the Elite ABC Nova Red kit (Vector Labs). Counterstaining was performed with Mayer's haematoxylin (1:4). The areas occupied by intracellular lipid vacuoles, UCP-1 and TH protein were quantified using ImageJ.

Statistical analysis Differences between groups were determined with the Kruskal-Wallis non-parametric test. When significant differences were found, the Mann-Whitney nonparametric test was used as a post hoc test to determine differences between two independent groups. Serum decay in the clearance experiment was analysed using repeatedmeasurements ANOVA with Tukey's post hoc test. A $p$ value of $<0.05$ was considered statistically significant. Data are presented as mean $\pm \mathrm{SD}$.

\section{Results}

Central GLP-1R activation decreases body weight and induces BAT activation in lean $\mathrm{C} 57 \mathrm{Bl} / 6 \mathrm{~J}$ mice Intracerebroventricular infusion of exendin-4 in lean $\mathrm{C} 57 \mathrm{Bl} / 6 \mathrm{~J}$ mice decreased body weight compared with controls (Fig. 1a, b), and this was accompanied by a reduced food intake (Fig. 1c), both of which are well-known effects of activation of the central GLP-1R system [3, 17]. Reduction of food intake per se, as shown by the control mice that were pair fed with the exendin4-treated mice (Fig. 1c), resulted in a reduction in body weight compared with controls that was delayed compared with that evoked by exendin-4 (Fig. 1a).

As central GLP-1 infusion increases sympathetic outflow towards BAT and WAT and subsequently stimulates thermogenesis $[12,13,18]$, we analysed the expression of $\mathrm{TH}$, a marker for activity of noradrenergic (norepiphrenergic) nerve fibres [19]. Exendin-4 increased the TH content in both iBAT $(+103 \%, p<0.01)$ and sWAT $(+331 \%, p<0.05)$ compared with controls (Fig. 1d, e). This increased sympathetic nervous system (SNS) signalling was accompanied by enhanced thermogenic capacity, as exendin-4 increased UCP-1 protein content in iBAT $(+44 \%, p<0.01)$ and sWAT $(+142 \%, p<0.05)$ compared with the control group (Fig. 1f, g), indicating more active BAT as well as browning of WAT. Reduction of food intake per se evoked similar increases in UCP-1 protein content in both BAT and WAT, but it was apparently independent of sympathetic input, which suggests the involvement of other pathways. The effects of exendin-4 on UCP-1 content were accompanied by a decreased lipid droplet content in BBAT $(-67 \%, p<0.001)$ and sWAT $(-53 \%, p<0.05)$ (Fig. 1h, i), probably as activation of BAT results in combustion of intracellular lipid stores as well as browning of WAT. The lipid content in BBAT was reduced to a greater extent in exendin4-treated mice than in food-restricted mice $(-46 \%, p<0.05)$, which coincided with a higher level of $\mathrm{TH}$, reflecting higher SNS activity towards BAT induced by exendin-4.

Central GLP-1R activation enhances uptake of plasma TG-derived fatty acids and glucose by BAT and browns WAT in lean C57BI/6J mice Subsequently, we tested our hypothesis that BAT activated during chronic GLP-1R activation is a major contributor to the plasma clearance of TG and glucose. To this end, mice were injected i.v. with $\left[{ }^{3} \mathrm{H}\right] \mathrm{TO}$-labelled TRL-like emulsion particles and $\left[{ }^{14} \mathrm{C}\right] \mathrm{DG}$. Indeed, exendin-4 accelerated the clearance of $\left[{ }^{3} \mathrm{H}\right] \mathrm{TO}$ from plasma (Fig. 2a). This enhanced clearance was the 
Fig. 1 Central GLP-1R

activation decreases body weight and food intake and induces activation of BAT in lean mice. Mice were treated for 5 days with i.c.v. exendin-4 $(n=8)$ or vehicle (control $n=9$, pair-fed $n=6$ ). On a daily basis, body weight $(\mathbf{a}, \mathbf{b})$ and food intake (c) were monitored. Samples of BAT and WAT were collected and stained for TH and UCP-1.

Representative pictures and quantification of TH (d, e), UCP1 (f, g) and lipid droplet content with $H \& E$ staining $(\mathbf{h}, \mathbf{i})$ are shown. Values are mean $\pm \mathrm{SD}$. ${ }^{*} p<0.05, * * p<0.01$ and $* * * p<0.001$ compared with control; ${ }^{\dagger} p<0.01$ compared with pair-fed control. White bars, control; black bars, exendin-4; grey bars, pair-fed control a

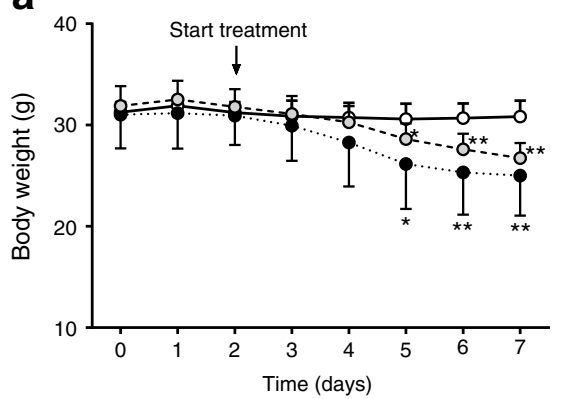

b

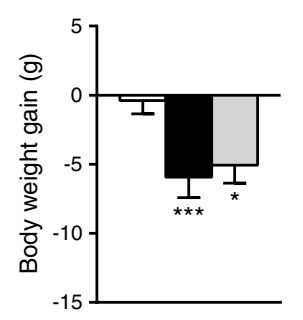

C

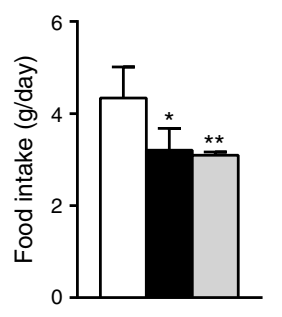

d

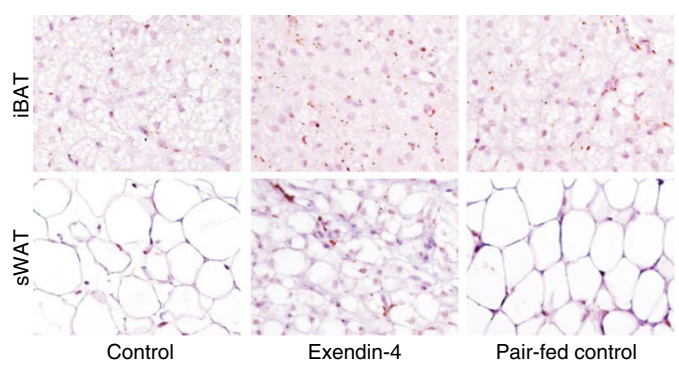

f

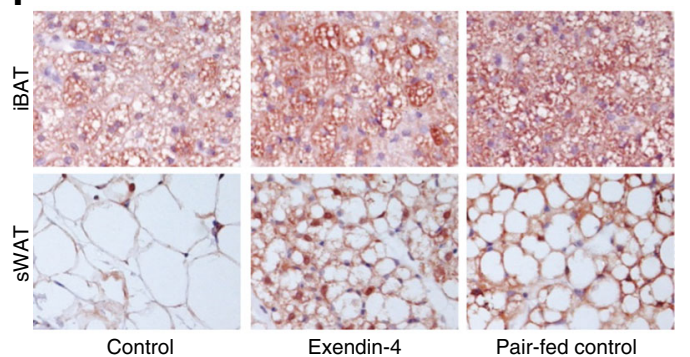

h

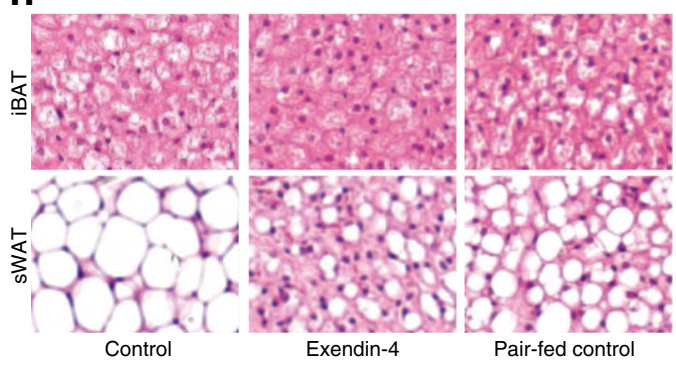

e

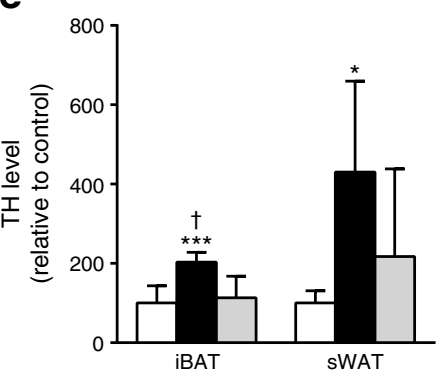

g

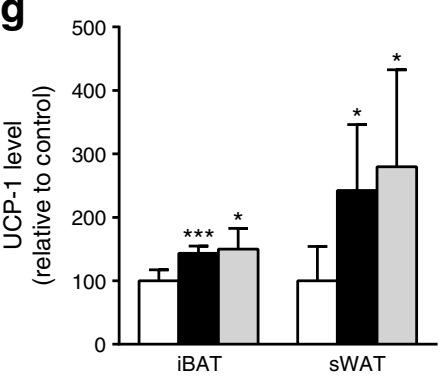

i

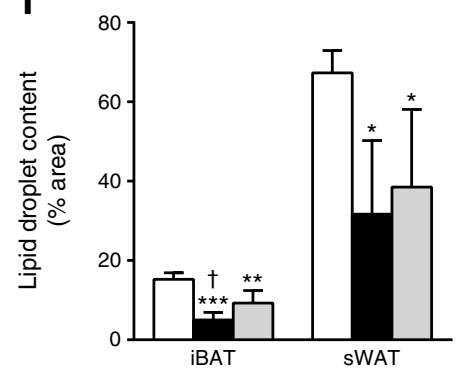

result of a greatly increased uptake of $\left[{ }^{3} \mathrm{H}\right] \mathrm{TO}$-derived activity by iBAT $(+276 \%, p<0.001$; Fig. 2 b). In addition, exendin- 4 enhanced the uptake of $\left[{ }^{3} \mathrm{H}\right] \mathrm{TO}$-derived activity by both sWAT $(+111 \%, p<0.01)$ and gonadal $(\mathrm{g})$ WAT $(+138 \%, p<0.05)$ compared with the control group, corresponding to the browning observed in these WAT depots. The pair-fed animals showed similar results for $\left[{ }^{3} \mathrm{H}\right] \mathrm{TO}$ kinetics as the exendin-4-treated group. Plasma clearance was increased (Fig. 2a), relating to a marked increase in the uptake of ${ }^{3} \mathrm{H}$ activity by iBAT compared with controlinfused animals $(+314 \%, p<0.001$; Fig. $2 b)$. In addition, the uptake by sWAT was increased $(+194 \%, p<0.05)$, whereas there was no significant effect on uptake by gWAT $(+109 \%, p=0.20)$ in pair-fed conditions.

Similar to plasma $\left[{ }^{3} \mathrm{H}\right] \mathrm{TO}$ clearance, chronic infusion of exendin- 4 accelerated the clearance of $\left[{ }^{14} \mathrm{C}\right] \mathrm{DG}$ from plasma (Fig. 2c). This enhanced clearance from the circulation was the result of an increased uptake of $\left[{ }^{14} \mathrm{C}\right] \mathrm{DG}$ by iBAT $(+142 \%, p<0.01)$ and skeletal muscle $(+40 \%, p<0.05)$ compared with controls (Fig. 2d). Interestingly, while the uptake of $\left[{ }^{3} \mathrm{H}\right] \mathrm{TO}$-derived activity by BAT in pair-fed mice was increased to a similar extent as in exendin- 4 treated animals, the uptake of $\left[{ }^{14} \mathrm{C}\right] \mathrm{DG}$ by iBAT was not increased in the pair-fed control mice. 
Fig. 2 Central GLP-1R activation increases uptake of plasma TG-derived fatty acids and glucose by BAT in lean mice. Mice were treated for 5 days via i.c.v. $(\mathbf{a}-\mathbf{d})$ or i.v. $(\mathbf{e}-\mathbf{f})$ routes with exendin-4 $(n=8)$ or vehicle (control $n=9$, pair-fed $n=6$ ). After treatment, mice were injected with $\left[{ }^{3} \mathrm{H}\right]$ TO-labelled particles and $\left[{ }^{14} \mathrm{C}\right] \mathrm{DG}$. Plasma ${ }^{3} \mathrm{H}$ activity (a) and ${ }^{14} \mathrm{C}$ activity (c) were plotted relative to the injected dose. At 15 min after injection, organs were isolated and uptake of ${ }^{3} \mathrm{H}$ activity $(\mathbf{b}, \mathbf{e})$ and ${ }^{14} \mathrm{C}$ activity (d, f) was determined. Values are mean \pm SD. ${ }^{*} p<0.05$, $* * p<0.01$ and $* * * p<0.001$ compared with control. ${ }^{\dagger} p<0.05$ and ${ }^{\dagger \dagger} p<0.01$ compared with pair-fed control. White bars/circles, control; black bars/circles, exendin-4; grey bars/circles, pair-fed control

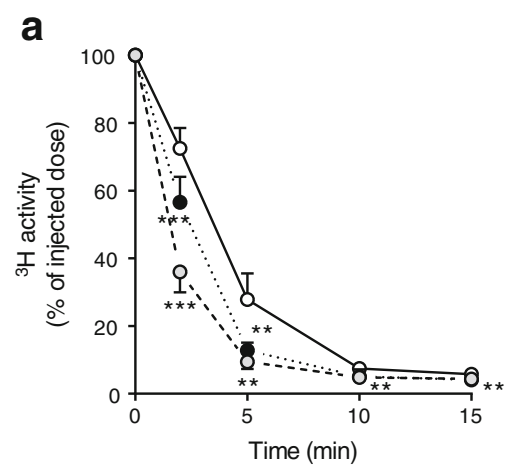

b
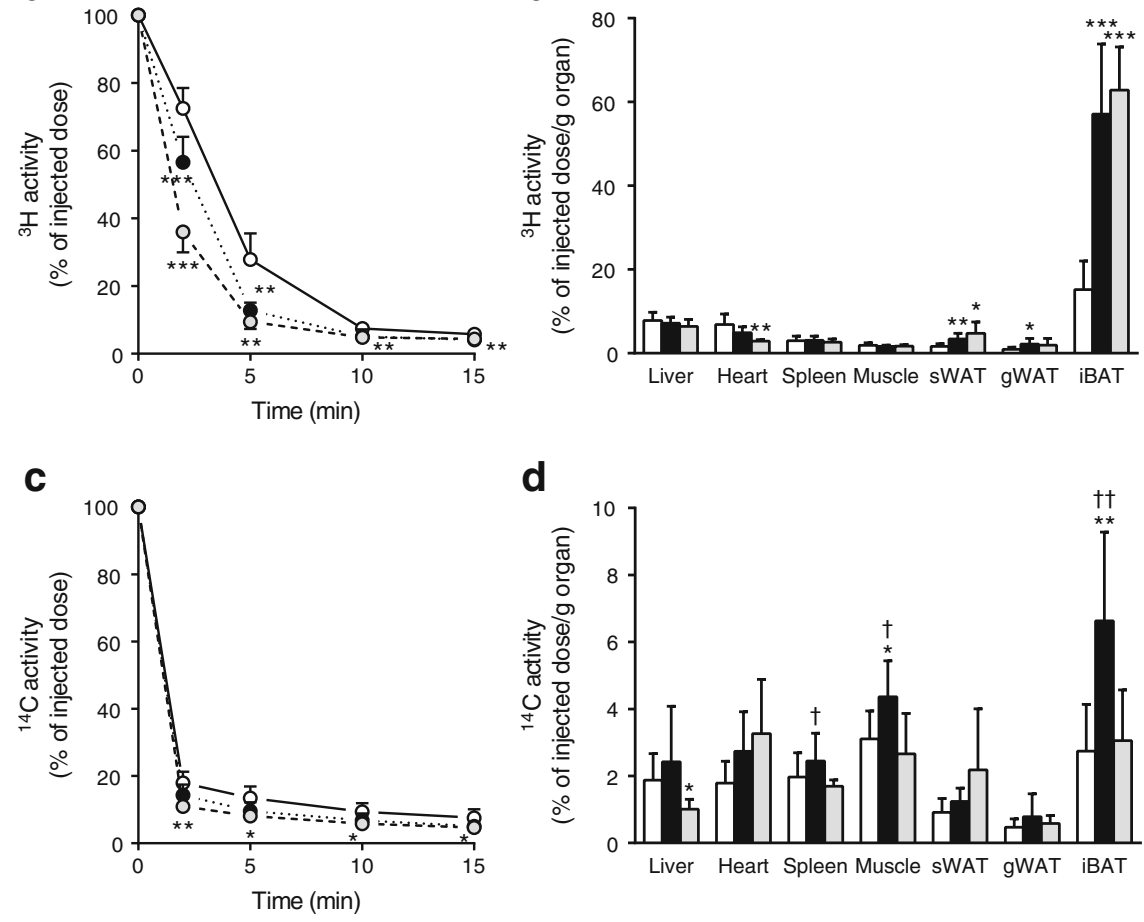

d

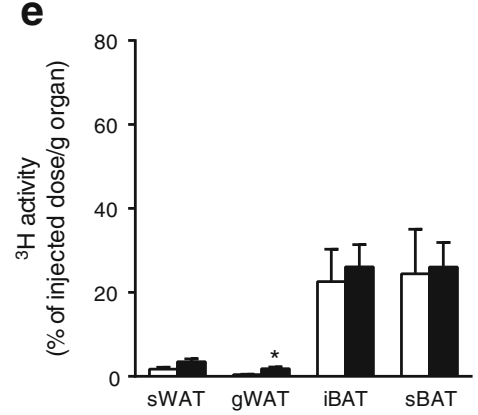

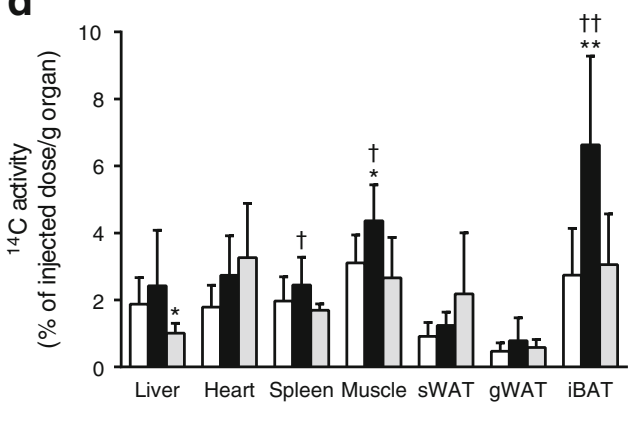

f

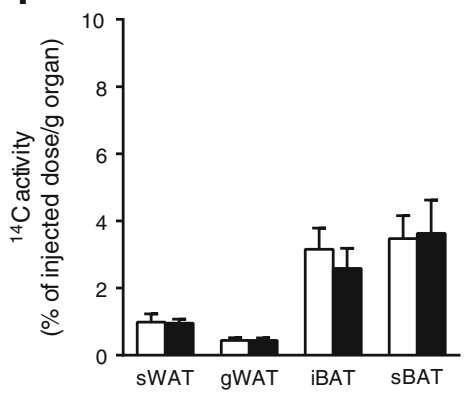

To rule out that the effects of i.c.v. administered exendin-4 on the uptake of TG-derived fatty acids and glucose by BAT were caused by leakage of exendin- 4 into the circulation, we next administered exendin- 4 peripherally at the same dose as administered centrally. Peripheral exendin- 4 treatment for 5 days delivered via subcutaneous minipumps did not enhance the uptake of $\left[{ }^{3} \mathrm{H}\right]$ TO-derived activity (Fig. 2e) or $\left[{ }^{14} \mathrm{C}\right] \mathrm{DG}$ (Fig. $2 \mathrm{f}$ ) by BAT. Peripheral exendin-4 only slightly increased the uptake of $\left[{ }^{3} \mathrm{H}\right] \mathrm{TO}$-derived activity by gWAT, possibly via a direct effect of GLP-1R signalling on white adipocyte formation [20].

Central GLP-1R activation decreases body weight, plasma TG and glucose levels, and shifts combustion from carbohydrates towards fat in DIO C57BI/6J mice To determine whether chronic i.c.v. exendin-4 infusion still leads to an increased uptake of plasma TG-derived fatty acids and glucose via BAT when obesity and insulin resistance have developed, we next explored the effects of central GLP-1R activation after 12 weeks of high-fat feeding. In DIO mice, continuous infusion of exendin-4 for 5 days decreased body weight compared with control-infused mice (Fig. 3a), which could only partly be attributed to reduced food intake (Fig. 3b) as the reduction in body weight was greater than in pair-fed controls. Determination of body composition showed that exendin-4 and pair feeding decreased body weight because of a selective decrease in fat mass compared with controls (Fig. 3c). Furthermore, plasma TG and glucose levels were both decreased from baseline values in the exendin-4-infused mice at the end of the treatment period (Table 1). In the pair-fed mice, plasma glucose levels were reduced from baseline values, but remained significantly higher than in the exendin-4-treated mice.

Indirect calorimetry showed that the decreased fat mass in the exendin-4-infused DIO mice was accompanied by an increased fat oxidation (Fig. 3d) at the expense of carbohydrate oxidation (Fig. 3e). This was also reflected in a decreased RER (Fig. 3f) compared with controls, suggesting a 
Fig. 3 Central GLP-1R activation decreases body weight and shifts combustion from carbohydrates towards fat in DIO mice. After 12 weeks of high-fat feeding, mice were treated for 5 days with i.c.v. exendin-4 ( $n=$ 10 ) or vehicle (control $n=6$, pairfed $n=9$ ). Body weight gain (a) and food intake (b) were determined. Lean (crossed area) and fat (no cross) mass were measured (c). During the treatment period, mice were housed in metabolic cages. Fatty acid oxidation (d), carbohydrate oxidation (e), RER (f) and energy expenditure (g) were calculated from $\mathrm{O}_{2}$ uptake and $\mathrm{CO}_{2}$ excretion. (h) Magnitude of physical activity in arbitrary units. Values are mean \pm SD. ${ }^{*} p<0.05$, $* * p<0.01$ and $* * * p<0.001$ compared with control. ${ }^{\dagger} p<0.05$ and ${ }^{\dagger \dagger} p<0.001$ compared with pair-fed control. White bars/continuous lines, control; black bars/dotted lines, exendin4; grey bars/dashed lines, pair-fed controls. AU, arbitrary units; $\mathrm{CH}$, carbohydrate; EE, energy expenditure; FA, fatty acid
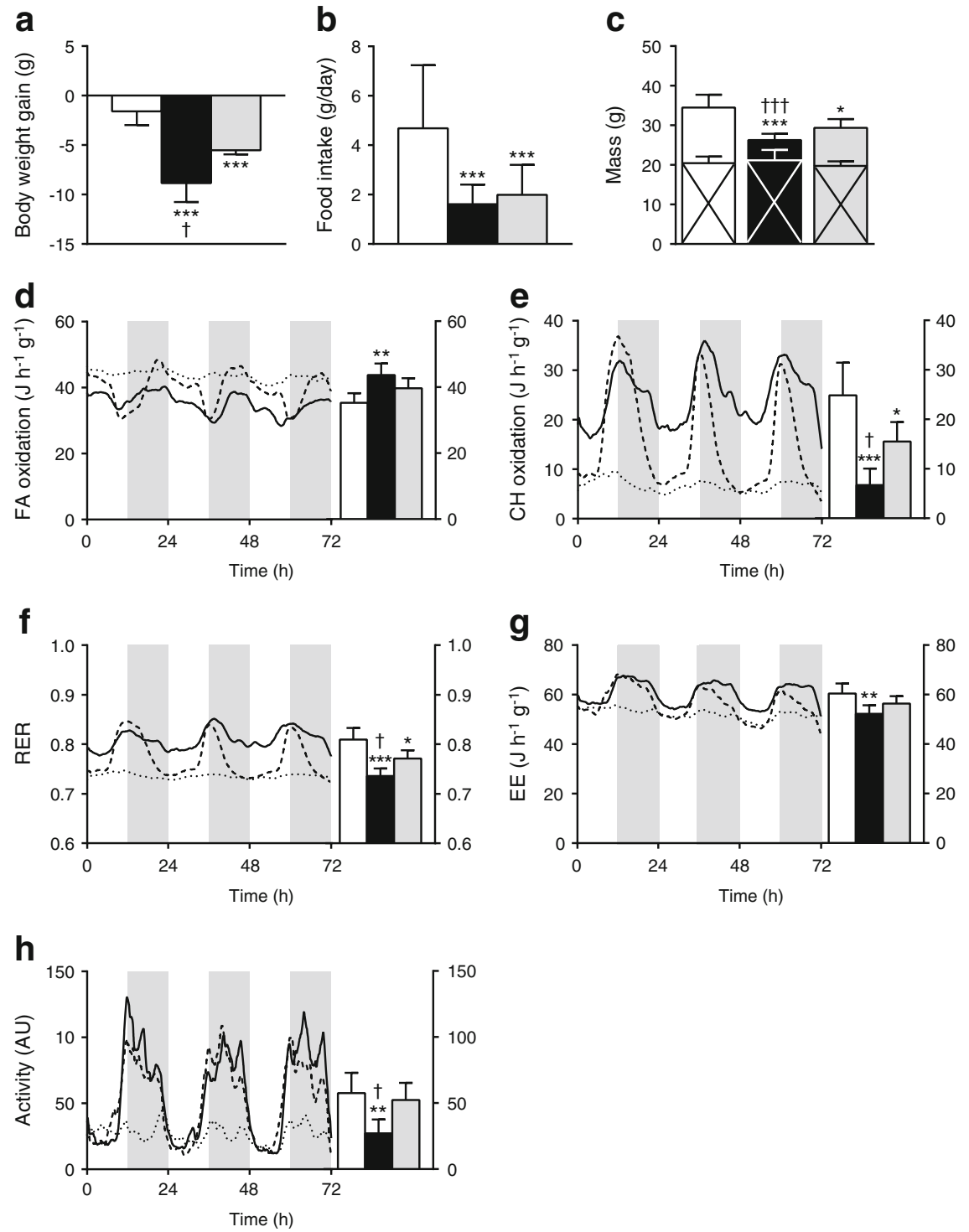

Table 1 Central GLP-1R activation decreases plasma TG and glucose levels in DIO mice

\begin{tabular}{ccll}
\hline Variable & Control & Exendin-4 & Pair-fed control \\
\hline TG (mmol/l) & & & \\
Start & $0.7 \pm 0.1$ & $0.7 \pm 0.1$ & $0.6 \pm 0.1$ \\
End & $0.7 \pm 0.5$ & $0.5 \pm 0.2^{*}$ & $0.6 \pm 0.4$ \\
\multicolumn{2}{c}{ Glucose (mmol/l) } & & \\
Start & $11.3 \pm 0.8$ & $11.6 \pm 1.1$ & $11.4 \pm 1.1$ \\
End & $10.6 \pm 0.9$ & $4.5 \pm 1.2^{* * *, \dagger \dagger}$ & $7.4 \pm 1.1^{* * *}$ \\
\hline
\end{tabular}

After 12 weeks of high-fat feeding, mice were treated for 5 days with i.c.v. exendin-4 $(n=10)$ or vehicle (control $n=6$, pair-fed $n=9)$. Blood was collected before and after treatment by tail bleeding after $4 \mathrm{~h}$ of fasting and plasma $\mathrm{TG}$ and glucose were determined

Values are mean $\pm \mathrm{SD}$

${ }^{*} p<0.05$ and ${ }^{* * *} p<0.001$ compared with baseline; ${ }^{\dagger \dagger} p<0.001$ compared with pair-fed control shift in nutrient combustion. Of note, exendin-4 reduced total energy expenditure (Fig. $3 \mathrm{~g}$ ) and decreased physical activity (Fig. 3h). Pair feeding also increased fat oxidation and decreased carbohydrate oxidation compared with the controls, but these effects were less pronounced than those of exendin-4. This implies that the effects of exendin-4 on energy metabolism are only partly caused by reduced food intake in DIO mice.

Central GLP-1R activation increases BAT thermogenesis, but does not induce browning of WAT in DIO C57BI/6J mice Under high-fat-fed conditions, i.c.v. exendin-4 treatment still increased SNS output towards BAT compared with controls, reflected by increased TH content (sBAT $+59 \%$, $p<0.05$ [not shown]; iBAT $+107 \%, p<0.01$, Fig. $4 \mathrm{a}$, b) and increased UCP-1 protein content (sBAT $+62 \%$ [not shown], $p<0.001$; iBAT $+93 \%, p<0.01$, Fig. 4 c, d), 
Fig. 4 Central GLP-1R activation increases TH and UCP1 protein levels and decreases lipid droplet content in BAT in DIO mice. After 12 weeks of high-fat feeding, mice were treated for 5 days with i.c.v. exendin-4 $(n=10)$ or vehicle (control $n=6$, pair-fed $n=9$ ). After treatment, mice were killed and BAT and WAT were collected and stained for TH and UCP-1.

Staining with $H \& E$ was performed for lipid droplet content. Representative pictures and quantification of $\mathrm{TH}(\mathbf{a}, \mathbf{b})$, UCP-1 (c, d) and lipid droplet content $(\mathbf{e}, \mathbf{f})$ are shown. Values are mean \pm SD. ${ }^{*} p<0.05$, $* * p<0.01$ and $* * * p<0.001$ compared with control. ${ }^{\dagger} p<0.01$ compared with pair-fed control. White bars, control; black bars, exendin-4; grey bars, pair-fed control a

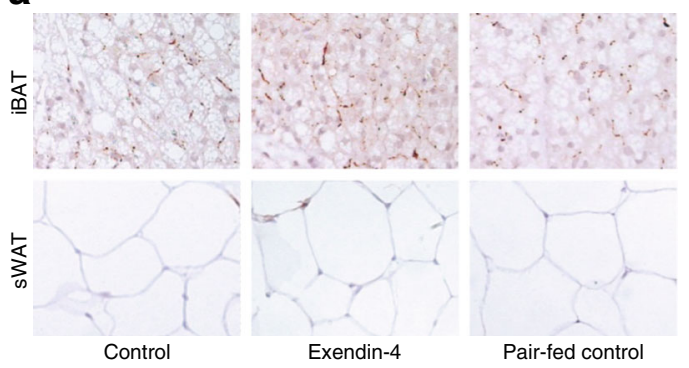

C

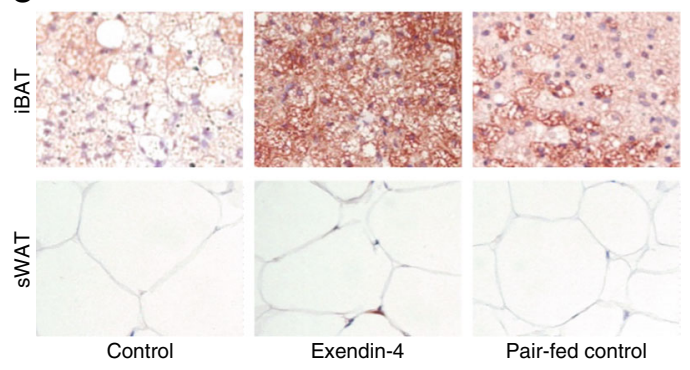

e
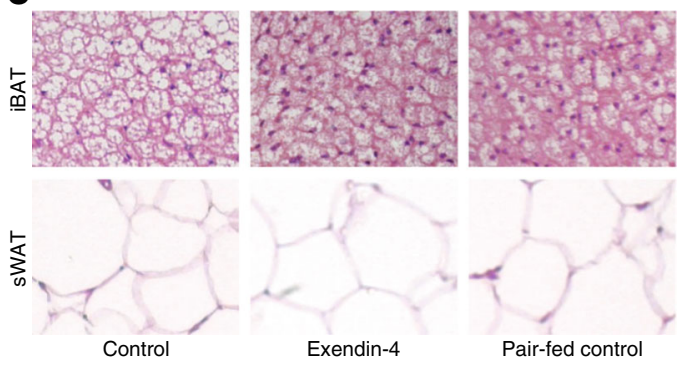

b

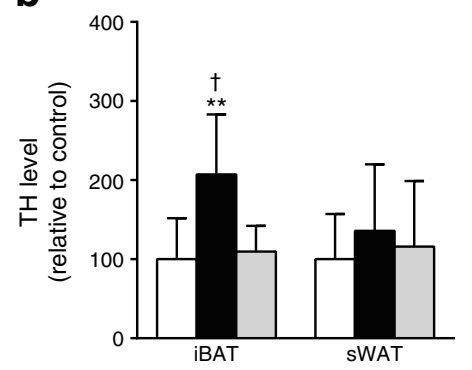

d

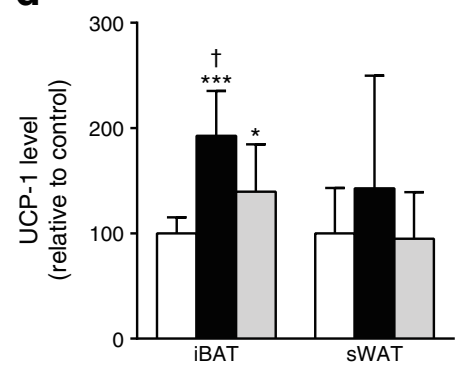

f

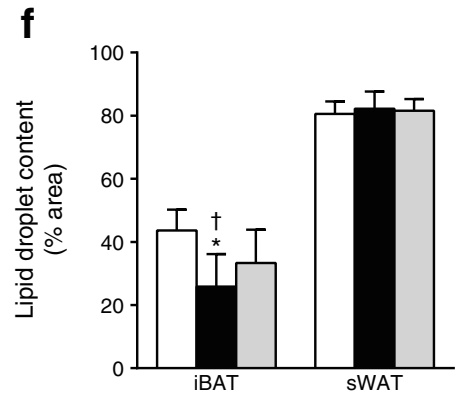

indicative of more active BAT. As a consequence, lipid droplet content was decreased in the exendin-4-treated animals compared with controls (sBAT $-49 \%, p<0.05$ [not shown]; iBAT $-41 \%, p<0.01$, Fig. 4 e, f). Pair feeding did not affect TH expression in BAT (Fig. 4a, b), slightly increased UCP-1 protein content (Fig. 4c, d) and slightly decreased lipid content (Fig. 4e, f) compared with controls. In contrast to the lean mice, infusion of exendin-4 in DIO mice did not induce browning of WAT as evidenced by unaffected TH expression, UCP-1 protein and lipid content.

\section{Central GLP-1R activation enhances TG and glucose} clearance by BAT in DIO C57BI/6J mice Similar to lean mice, chronic i.c.v. infusion of exendin-4 in DIO mice accelerated the plasma clearance of $\left[{ }^{3} \mathrm{H}\right] \mathrm{TO}$ (Fig. 5a) and $\left[{ }^{14} \mathrm{C}\right] \mathrm{DG}$ (Fig. 5c). This was accompanied by a selectively increased uptake of $\left[{ }^{3} \mathrm{H}\right]$ TO-derived activity and $\left[{ }^{14} \mathrm{C}\right] \mathrm{DG}$ by iBAT $(+$ $291 \%, p<0.001$ and $+482 \%, p<0.001$, respectively) and sBAT $(+217 \%, p<0.01$ and $+247 \%, p<0.001$, respectively) (Fig. 5b, d). Despite the lack of evidence for browning of WAT, exendin- 4 enhanced the uptake of both $\left[{ }^{3} \mathrm{H}\right]$ TO-derived activity and $\left[{ }^{14} \mathrm{C}\right] \mathrm{DG}$ by both sWAT $(+146 \%, p<0.05$ and $+93 \%, p<0.05)$ and gWAT $(+69 \%, p<0.01$ and $+82 \%$, $p<0.01)$. To some extent, the pair-fed animals showed similar results on $\left[{ }^{3} \mathrm{H}\right] \mathrm{TO}$ and $\left[{ }^{14} \mathrm{C}\right] \mathrm{DG}$ kinetics as the exendin- 4 treated mice. Plasma clearance was increased (Fig. 5a, c), associated with a marked increase in uptake of $\left[{ }^{3} \mathrm{H}\right] \mathrm{TO}$-derived activity and $\left[{ }^{14} \mathrm{C}\right] \mathrm{DG}$ by $\mathrm{iBAT}(+170 \%, p<0.01$ and $+482 \%, p<0.001$, respectively) and sBAT $(+188 \%, p<0.001$ and $+247 \%, p<0.001$, respectively) compared with controlinfused animals (Fig. 5b, d). Interestingly, the uptake of $\left[{ }^{3} \mathrm{H}\right]$ TO-derived activity by iBAT and the uptake of $\left[{ }^{14} \mathrm{C}\right] \mathrm{DG}$ by $\mathrm{iBAT}$ and $\mathrm{SBAT}$ were significantly lower compared with the exendin-4-treated mice $(-31 \%, p<0.05,-63 \%, p<0.01$ and $-43 \%, p<0.01$, respectively), indicating that exendin- 4 exerts its effects partly independent of lowering food intake.

\section{Discussion}

In the present study we show that central GLP-1R activation by exendin- 4 increases the plasma clearance of TG and glucose in both lean and DIO C57B1/6J mice via increased uptake of TG-derived fatty acids and glucose by BAT, accompanied by activation of BAT and browning of WAT. 
Fig. 5 Central GLP-1R activation increases uptake of plasma TG-derived fatty acids and glucose by BAT in DIO mice. After 12 weeks of high-fat feeding, mice were treated for 5 days with i.c.v. exendin-4 ( $n=$ 10 ) or vehicle (control $n=6$, pairfed $n=9$ ). After treatment, mice were injected with $\left[{ }^{3} \mathrm{H}\right] \mathrm{TO}-$ labelled particles and $\left[{ }^{14} \mathrm{C}\right] \mathrm{DG}$. Plasma ${ }^{3} \mathrm{H}$ activity (a) and ${ }^{14} \mathrm{C}$ activity (c) were plotted relative to the injected dose. At 15 min after injection, organs were isolated and uptake of the ${ }^{3} \mathrm{H}$ activity (b) and ${ }^{14} \mathrm{C}$ activity (d) was determined. Values are mean \pm SD. $* p<0.05, * * p<0.01$ and $* * * p<0.001$ compared with control. ${ }^{\dagger} p<0.05$ and ${ }^{\dagger \dagger} p<0.01$ compared with pair-fed control. White bars, control; black bars, exendin-4; grey bars, pair-fed control a

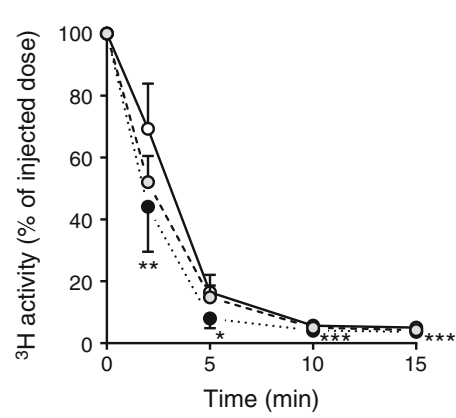

C

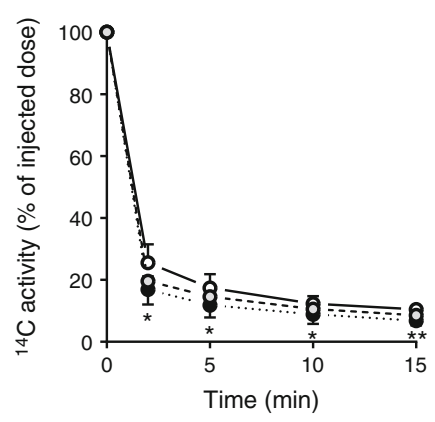

b

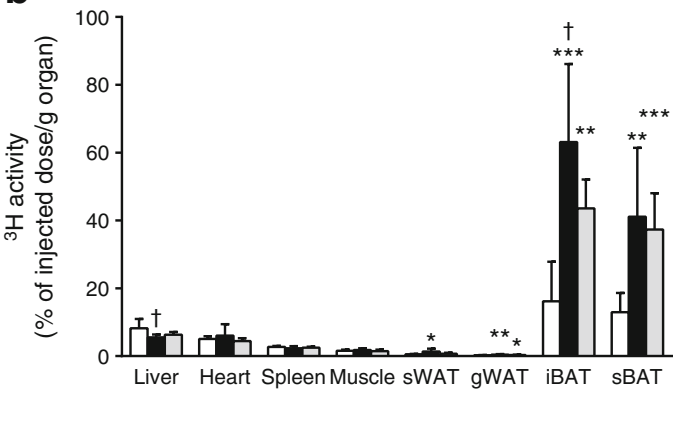

d

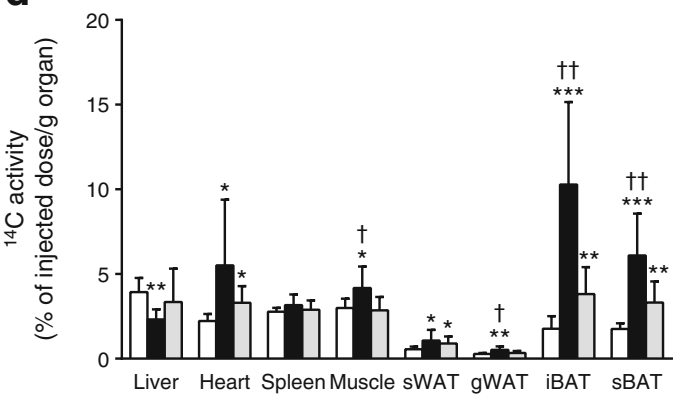

First, we showed that continuous central infusion of the GLP-1R analogue exendin-4 (5 days, $0.75 \mathrm{nmol} /$ day) evokes the well-known effect of reducing food intake and body weight $[3,17]$. In addition, central administration of exendin-4 increased SNS activity towards BAT and WAT, as evidenced by increased TH and UCP-1 protein content and lowered lipid content. This corroborates previous findings demonstrating the essential role of the SNS in BAT and WAT activation by central GLP-1R signalling [12, 18]. Exendin-4 also caused a robustly accelerated clearance of plasma TG and glucose, which likely contributed to reduced plasma TG and glucose concentrations observed in DIO mice. Strikingly, the uptake of TG-derived activity, presumably $\left[{ }^{3} \mathrm{H}\right]$ oleate liberated by lipoprotein lipase (LPL) [11], was not only increased by BAT but also by WAT, together with the increase in UCP-1 content indicative of so-called browning. Although activation of BAT and WAT are likely involved in the observed reduction of plasma TG and glucose by central exendin- 4 , further studies are warranted to investigate the quantitative contribution of GLP-1R signalling towards BAT and WAT to the overall metabolic improvements on GLP-1R agonism.

It has been reported that central GLP-1 infusion reduces the lipid content of WAT in lean mice but not DIO mice [18], suggesting that some resistance to the actions of central GLP-1 is induced in DIO mice. Clearly, this effect is not desirable for a drug to treat obesity. Therefore, we explored the effects of chronic central exendin- 4 infusion after 12 weeks of high-fat feeding, sufficient to induce obesity and insulin resistance in this mouse model $[21,22]$. Our results show that under these conditions, chronic central GLP-1R signalling still improves the clearance of plasma TG and glucose via a robustly increased uptake by BAT. However, central GLP-1R agonism did not alter UCP-1 protein content or lipid droplet content in WAT in DIO mice, consistent with previous findings by Nogueiras et al [18]. It is interesting to speculate on why, during obesity, WAT is not susceptible to browning on exendin-4 treatment. Previous studies reported a decreased sensitivity of white adipocytes to adrenergic stimulation in obese individuals [23]. However, in our study we also describe the absence of exendin-4-induced TH expression in WAT in DIO mice. It is possible that different brain areas modulate specific BAT and WAT functions. While multiple tissues are simultaneously sympathetically stimulated during cold exposure, there are many examples of treatments that result in differential sympathetic outflow to various types of tissues (e.g. WAT vs BAT) and even within a type of tissue (e.g. different WAT pads) [24]. The GLP-1R is widely expressed through the hypothalamus [25], and exerts effects via different nuclei. For example, GLP-1R signalling in the arcuate nucleus regulates glucose metabolism, while it modulates feeding via the paraventricular nucleus [5]. Altogether, it is likely that GLP-1R signalling and subsequent sympathetic outflow differ during obesity and lean conditions.

In apparent contrast to the notion that increased BAT activity is generally correlated with an enhanced total energy expenditure [26], central GLP-1R activation in fact reduced total energy expenditure, an effect we have observed before during 
chronic peripheral exendin-4 treatment [27]. Possibly, the reduction in energy intake is compensated by a relative reduction in energy expenditure. In addition, it appears that chronic central GLP-1R activation results in a shift from using carbohydrates to fatty acids as an energy source, which is consistent with previous studies that showed that chronic i.c.v. GLP-1 treatment decreased the respiratory quotient, indicative of a higher level of fat oxidation by BAT $[18,28]$. The exendin4-induced decrease in physical activity, resulting from a diminished food-seeking behaviour [29], is less likely to contribute to the change in total energy expenditure [30].

From a clinical perspective, the possibility that BAT activity in humans may be amenable to pharmacological manipulation by GLP-1R agonism to control insulin sensitivity and body weight is attractive but, as yet, undemonstrated. Drugs targeting the GLP-1R system are already widely prescribed for their incretin properties to treat type 2 diabetes, but they may be useful in a wider context related to energy balance. The resting energy expenditure of obese individuals with type 2 diabetes increases with 1 year of treatment with a combination of metformin and exenatide or liraglutide [13]. It is tempting to speculate that BAT may be activated in these patients. Increasing our knowledge about the mechanism of action of exendin-4 may add to the (further) development of peptidomimetics in our battle against obesity and type 2 diabetes.

In conclusion, our results show that chronic central infusion of exendin-4 increases SNS output to enhance BAT activity in both lean and DIO C57B1/6J mice. Via highly active BAT, the plasma clearance of TG and glucose is accelerated and body fat content is decreased, which, together with reduced food intake, leads to a decrease in body weight. Therefore, we suggest that GLP-1R agonists via BAT activation reduce both hyperlipidaemia and hyperglycaemia, and possibly even atherosclerosis [31], in addition to the effects of BAT activation on obesity.

Funding We acknowledge the support from the Netherlands CardioVascular Research Initiative: 'the Dutch Heart Foundation, Dutch Federation of University Medical Centers, the Netherlands Organisation for Health Research and Development and the Royal Netherlands Academy of Sciences' for the projects 'Generating the best evidence-based pharmaceutical targets for atherosclerosis' (GENIUS; CVON2011) and 'Targeting energy metabolism to combat cardiovascular disease' (ENERGISE; CVON2014). MRB was supported by a grant from the Board of Directors of LUMC and is supported by a Rubicon grant from ZonMW (825.13.021). PCNR is an Established Investigator of the Netherlands Heart Foundation (grant 2009T038).

Contribution statement ETP and SK contributed to study design, data acquisition and analysis and wrote the manuscript. YW, MRB, DE and GS contributed to data acquisition and analysis and drafted the manuscript. HP, JAR and PCNR contributed to design of the study and interpretation of data and edited the manuscript for intellectual content. All authors gave final approval of the version to be published. SK and PCNR are responsible for the integrity of the work as a whole.
Duality of interest The authors declare that there is no duality of interest associated with the manuscript.

Open Access This article is distributed under the terms of the Creative Commons Attribution 4.0 International License (http:// creativecommons.org/licenses/by/4.0/), which permits unrestricted use, distribution, and reproduction in any medium, provided you give appropriate credit to the original author(s) and the source, provide a link to the Creative Commons license, and indicate if changes were made.

\section{References}

1. Gallwitz B (2011) Glucagon-like peptide-1 analogues for Type 2 diabetes mellitus: current and emerging agents. Drugs 71:16751688

2. Hwa JJ, Ghibaudi L, Williams P, Witten MB, Tedesco R, Strader CD (1998) Differential effects of intracerebroventricular glucagonlike peptide-1 on feeding and energy expenditure regulation. Peptides 19:869-875

3. Turton MD, O'Shea D, Gunn I et al (1996) A role for glucagon-like peptide-1 in the central regulation of feeding. Nature 379:69-72

4. Knauf C, Cani PD, Perrin C et al (2005) Brain glucagon-like peptide-1 increases insulin secretion and muscle insulin resistance to favor hepatic glycogen storage. J Clin Invest 115:3554-3563

5. Sandoval DA, Bagnol D, Woods SC, D'Alessio DA, Seeley RJ (2008) Arcuate glucagon-like peptide 1 receptors regulate glucose homeostasis but not food intake. Diabetes 57:2046-2054

6. Parlevliet ET, de Leeuw van Weenen JE, Romijn JA, Pijl H (2010) GLP-1 treatment reduces endogenous insulin resistance via activation of central GLP-1 receptors in mice fed a high-fat diet. Am J Physiol Endocrinol Metab 299:E318-E324

7. Boon MR, van den Berg SA, Wang Y et al (2013) BMP7 activates brown adipose tissue and reduces diet-induced obesity only at subthermoneutrality. PLoS One 8, e74083

8. Geerling JJ, Boon MR, van der Zon GC et al (2014) Metformin lowers plasma triglycerides by promoting VLDL-triglyceride clearance by brown adipose tissue in mice. Diabetes 63:880-891

9. Bartelt A, Bruns OT, Reimer R et al (2011) Brown adipose tissue activity controls triglyceride clearance. Nat Med 17:200-205

10. Emanuelli B, Vienberg SG, Smyth G et al (2014) Interplay between FGF21 and insulin action in the liver regulates metabolism. J Clin Invest 124:515-527

11. Khedoe PP, Hoeke G, Kooijman S et al (2015) Brown adipose tissue takes up plasma triglycerides mostly after lipolysis. J Lipid Res 56:51-59

12. Lockie SH, Heppner KM, Chaudhary N et al (2012) Direct control of brown adipose tissue thermogenesis by central nervous system glucagon-like peptide-1 receptor signaling. Diabetes 61:2753-2762

13. Beiroa D, Imbernon M, Gallego R et al (2014) GLP-1 agonism stimulates brown adipose tissue thermogenesis and browning through hypothalamic AMPK. Diabetes 63:3346-3358

14. Coomans CP, Biermasz NR, Geerling JJ et al (2011) Stimulatory effect of insulin on glucose uptake by muscle involves the central nervous system in insulin-sensitive mice. Diabetes 60:3132-3140

15. Rensen PC, Herijgers N, Netscher MH, Meskers SC, van Eck M, van Berkel TJ (1997) Particle size determines the specificity of apolipoprotein E-containing triglyceride-rich emulsions for the LDL receptor versus hepatic remnant receptor in vivo. J Lipid Res 38:1070-1084

16. Van Klinken JB, van den Berg SA, Havekes LM, van Willems DK (2012) Estimation of activity related energy expenditure and resting metabolic rate in freely moving mice from indirect calorimetry data. PLoS One 7, e36162 
17. Al-Barazanji KA, Arch JR, Buckingham RE, Tadayyon M (2000) Central exendin-4 infusion reduces body weight without altering plasma leptin in (fa/fa) Zucker rats. Obes Res 8:317-323

18. Nogueiras R, Perez-Tilve D, Veyrat-Durebex C et al (2009) Direct control of peripheral lipid deposition by CNS GLP-1 receptor signaling is mediated by the sympathetic nervous system and blunted in diet-induced obesity. J Neurosci 29:5916-5925

19. Giordano A, Frontini A, Cinti S (2008) Adipose organ nerves revealed by immunohistochemistry. Methods Mol Biol 456:83-95

20. Challa TD, Beaton N, Arnold M, Rudofsky G, Langhans W, Wolfrum C (2012) Regulation of adipocyte formation by GLP-1/ GLP-1R signaling. J Biol Chem 287:6421-6430

21. Korsheninnikova E, van der Zon GC, Voshol PJ et al (2006) Sustained activation of the mammalian target of rapamycin nutrient sensing pathway is associated with hepatic insulin resistance, but not with steatosis, in mice. Diabetologia 49:3049-3057

22. Surwit RS, Kuhn CM, Cochrane C, McCubbin JA, Feinglos MN (1988) Diet-induced type II diabetes in C57BL/6J mice. Diabetes 37: 1163-1167

23. van Baak MA (2001) The peripheral sympathetic nervous system in human obesity. Obes Rev 2:3-14

24. Bartness TJ, Song CK (2007) Brain-adipose tissue neural crosstalk. Physiol Behav 91:343-351

25. Goke R, Larsen PJ, Mikkelsen JD, Sheikh SP (1995) Distribution of GLP-1 binding sites in the rat brain: evidence that exendin-4 is a ligand of brain GLP-1 binding sites. Eur J Neurosci 7:22942300

26. Cannon B, Nedergaard J (2004) Brown adipose tissue: function and physiological significance. Physiol Rev 84:277-359

27. Parlevliet ET, Wang Y, Geerling JJ et al (2012) GLP-1 receptor activation inhibits VLDL production and reverses hepatic steatosis by decreasing hepatic lipogenesis in high-fat-fed APOE*3-Leiden mice. PLoS One 7, e49152

28. Tachibana T, Oikawa D, Adachi N, Boswell T, Furuse M (2007) Intracerebroventricular injection of glucagon-like peptide-1 changes lipid metabolism in chicks. Comp Biochem Physiol A Mol Integr Physiol 147:1104-1108

29. Dickson SL, Shirazi RH, Hansson C, Bergquist F, Nissbrandt H, Skibicka KP (2012) The glucagon-like peptide 1 (GLP-1) analogue, exendin- 4 , decreases the rewarding value of food: a new role for mesolimbic GLP-1 receptors. J Neurosci 32: $4812-4820$

30. Virtue S, Even P, Vidal-Puig A (2012) Below thermoneutrality, changes in activity do not drive changes in total daily energy expenditure between groups of mice. Cell Metab 16:665-671

31. Berbee JF, Boon MR, Khedoe PP et al (2015) Brown fat activation reduces hypercholesterolaemia and protects from atherosclerosis development. Nat Commun 6:6356 